\title{
Cutaneous adverse events associated with long-term immunomodulating therapy in multiple sclerosis
}

\author{
Deepak MW Balak ${ }^{* *}$, Gerald JD Hengstman ${ }^{2,3}$, Raymond Hupperts ${ }^{4}, \mathrm{H}$ Bing Thio ${ }^{1}$ \\ From 6th European Workshop on Immune-Mediated Inflammatory Diseases \\ Nice, France. 23-25 November 2011
}

\section{Introduction}

Multiple sclerosis (MS) is a common immune-mediated inflammatory disease of the central nervous system that causes severe neurological disability [1]. Treatment is aimed at reducing disease progression via modulation of the immune system with disease-modifying therapies (DMTs) such as glatiramer acetate (GA) and interferon beta (IFN beta) [2]. Skin reactions to DMT are common and involve localized inflammatory processes [3].

\section{Aim}

Our aim was to assess the prevalence and type of cutaneous adverse events associated with long-term use of DMT.

\section{Methods}

A cross-sectional study was conducted in 2010-2011 among 15 clinics in the Netherlands. Eligible for inclusion were MS patients who were treated with their first DMT for at least 2 years. All consecutive eligible patients willing to participate were enrolled, irrespective of the presence of skin reactions. Skin reactions were assessed from digital photographs of the injection-sites by dermatologists, who were blinded for the DMT.

\section{Results}

A total of 146 patients were enrolled. The median age was 47 years (interquartile range [IQR] 41-54 years) and most patients $(76 \%)$ were female. The median duration of DMT treatment was 4 years (IQR 3-8). Forty-four (30\%) patients were treated with intramuscular (IM) IFN beta1a, 43 (29\%) with subcutaneous (SC) IFN beta-1a,
38 (26\%) with IFN beta-1b, and 21 (14\%) with GA. The proportion of patients with cutaneous adverse events was $40 \%, 77 \%, 63 \%$, and $81 \%$ among patients receiving IM IFN beta-1a, SC IFN beta-1a, SC IFN beta-1b, and GA, respectively. Skin reactions were local injection-site reactions $(61 \%)$, lipoatrophy $(24 \%)$, healed skin ulcers (7\%), postinflammatory hyperpigmentation $(4 \%)$, urticaria $(3 \%)$, and skin necrosis (1\%).

\section{Conclusion}

The prevalence of cutaneous adverse events associated with DMT treatment was high. The most common skin reactions were local injection-site reactions and lipoatrophy related to panniculitis.

\section{Author details}

'Dept. of Dermatology, Erasmus Medical Center, Rotterdam, The Netherlands. ${ }^{2}$ Dept. of Neurology, Catharina Ziekenhuis, Eindhoven, The Netherlands.

${ }^{3}$ Regionaal MS Centrum Oost-Brabant, Eindhoven, The Netherlands.

${ }^{4}$ Academic MS Centre Limburg, Orbis Medical Centre, Sittard, The Netherlands.

Published: 23 November 2011

\section{References \\ 1. Frohman EM, Racke MK, Raine CS: Multiple sclerosis-the plaque and its pathogenesis. N Engl J Med 2006, 354(9):942-55. \\ 2. Compston A, Coles A: Multiple sclerosis. Lancet 2008, 372(9648):1502-17. \\ 3. Buttmann M, Goebeler M, Toksoy A, Schmid S, Graf W, Berberich-Siebelt F, Rieckmann P: Subcutaneous interferon-beta injections in patients with multiple sclerosis initiate inflammatory skin reactions by local chemokine induction. J Neuroimmunol 2005, 168(1-2):175-82.}

doi:10.1186/1479-5876-9-S2-P14

Cite this article as: Balak et al: Cutaneous adverse events associated with long-term immunomodulating therapy in multiple sclerosis. Journal of Translational Medicine 2011 9(Suppl 2):P14.

'Dept. of Dermatology, Erasmus Medical Center, Rotterdam, The Netherlands Full list of author information is available at the end of the article

(C) 2011 Balak et al; licensee BioMed Central Ltd. This is an open access article distributed under the terms of the Creative Commons Attribution License (http://creativecommons.org/licenses/by/2.0), which permits unrestricted use, distribution, and reproduction in any medium, provided the original work is properly cited. 